\title{
Analisis Antrian Pada Stasiun Pengisian Bahan Bakar Umum (SPBU) 34-151-28 Jatiuwung Tangerang
}

\author{
Khamaludin $^{1)}$ Faiz Al Iksan ${ }^{2)}$ Rama Putra I K $^{3)}$ Santika $^{4)}$ dan Dedi Wahyudi ${ }^{* *}$ \\ Jurusan Teknik Industri, Fakultas Teknik, Universitas Islam Syekh Yusuf, Jl. Mulana Yusuf \\ No.10 Tangerang Banten 15118, Indonesia (10pt normal italic)

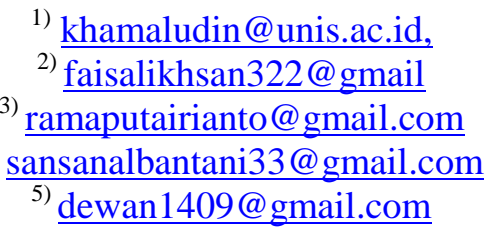

\begin{abstract}
Abstrak. Masalah antrian berhubungan dengan efesiensi dimana terjadinya antrian akan mengurangi kenyamanan pelayanan kepada pelanggan. Hal ini juga salah satunya yang terjadi di Stasiun Pengisian Bahan Bakar Umum(SPBU) 34-151-28 Jatiuwung, antrian ini terjadi karena banyaknya fasilitas yang tidak sebanding dengan laju kedatangan pelanggan, sehingga kinerja pelayanan antrian belum optimal. Tujuan dari penelitian ini adalah untuk menganalisis kinerja pelayan sistem antrian (SPBU) 34-151-28 Jatiuwung. Untuk membuktikan dugaan ini diadakan penelitian langsung ke lapangan dengan landasan teori yang dianggap relevan, yaitu teori antrian atau line theory. Penelitian ini dilakukan di Jatiuwung selama enam hari. Pengumpulan data pada studi kuantitatif ini menggunakan data primer yaitu observasi serta wawancara dan juga data sekunder yang diperoleh dari perusahaan dan juga diperoleh dari berbagai pustaka dan literature lainnya yang memiliki relevansi dengan sasaran penelitian seperti buku-buku teks mengenai sistem antrian. Analisis dari penelitian ini membuktikan bahwa kegiatan pelayanan antrian pada (SPBU) 34-151-28 Jatiuwung Tangerang sudah optimal karena lama pelanggan mengantri masih berada di bawah standar pelayanan yang ditetapkan SPBU 34-151-28 Jatiuwung Tangerang. Alat analisis dari penelitian ini adalah model antrian M/M/S (Multiple Channel Query System atau model antrian jalur berganda).Model yang diterapkan di SPBU 34-151-28 Jatiuwung Tangerang dengan 4 buah stasiun pengisian, dan berdasarkan perhitungannya SPBU 34-15128 Jatiuwung Tangerang sudah optimal karena waktu terpanjang selama 480 detik yang dibutuhkan oleh seorang pelanggan dalam antrian tidak melebihi dari batas standar yaitu 31.5 detik. SPBU Jatiuwung Tangerang sudah cukup meningkatkan kinerja pelayanannya.
\end{abstract}

Kata kunci: antrian, pelayanan, pelanggan

\begin{abstract}
The queue problem is related to the efficiency in which the queue will reduce the convenience of service to the customer. This is also one of the occurrences in Public Fuel Filling Station (SPBU) 34-151-28 Jatiuwung, this queue occurs because the number of facilities that are not comparable with the rate of arrival of the customer, so that the queue service performance has not been optimal. The purpose of this research is to analyze the performance of queue system (SPBU) 34-151-28 Jatiuwung. To prove this allegation held direct research into the field with the foundation of the theory considered relevant, ie queuing theory or line theory. This research was conducted in Jatiuwung for six days. Data collection in this quantitative study uses primary data, ie observation and interviews and also secondary data obtained from the company and also obtained from various libraries and other literature that has relevance to the target research such as textbooks on the queuing system. The analysis of this study proves that the queue service activity at (SPBU) 34-151-28 Jatiuwung Tangerang is optimal because the long time customers queue is still below the service
\end{abstract}


standards set filling stations 34-151-28 Jatiuwung Tangerang. Analyzer from this research is M/M/S queuing model (Multiple Channel Query System or multiple track queuing model). Model applied at gas station 34-151-28 Jatiuwung Tangerang with 4 filling stations, and based on the calculation of gas station 34-151 -28 Jatiuwung Tangerang is optimal because the longest time for 480 seconds required by a customer in the queue does not exceed the standard limit of 31.5 seconds. Gas stations Jatiuwung Tangerang is enough to improve the performance of its services.

Keywords: queue, service, customer

\section{Pendahuluan}

SPBU 34-151-28 Jatiuwung Tangerang merupakan salah satu stasiun pengisian bahan bakar umum yang terletak di Jalan Gatot Subroto, Jatiuwung, Kota Tangerang, Banten 15138. SPBU34-151-28 Jatiuwung ini menyediakan dua fasilitas pengisian bahan bakar untuk pengendara mobil dan motor, dengan jenis bahan bakar pertamax, pertalite dan premium. Terdapat dua jalur untuk pengendara sepeda motor, yang diharapkan dapat mengurangi masalah antrian ketika pelanggan datang pada saat tertentu untuk memenuhi kebutuhannya. Namun, seiring dengan kemajuan zaman di semua sektor yang menyebabkan pengguna sepeda motor saat ini mengalami peningkatan dan keinginan pelanggan yang sama saat ingin memenuhi kebutuhan akan bahan bakar pada saat-saat tertentu dapat menyebabkan masalah antrian, karena jumlah fasilitas yang kurang untuk memenuhi pelayanan pelanggan.

Mencegah timbulnya antrian atau mngurangi antrian yang panjang adalah menggunakan cara, menganalisis sistem antrian SPBU34-151-28 Jatiuwung dengan menerapkan teori antrian. Analisis dilakukan dengan mengadakan penelitian di mana antrian yang panjang terjadi, bertujuan agar keputusan yang diambil dari hasil analisis dapat berlaku untuk berbagai kondisi pelayanan, sehingga analisis dapat memberikan masukan yang bermanfaat untuk menyelesaikan masalah dengan lebih optimal.

Berdasarkan uraian pada latar belakang masalah, maka dirumuskan permasalahannya itu, apakah kinerja pelayanan sistem antrian dan fasilitas untuk pengisian bahan bakar pada SPBU34-151-28 Jatiuwung Tangerang sudah optimal? Berdasarkan rumusan masalah di atas, maka tujuan penelitian ini adalah untuk menganalisis kinerja pelayanan sistem antrian SPBU34-151-28 Jatiuwung Tangerang.
Manajemen operasi (operation management) adalah serangkaian aktivitas yang menghasilkan nilai dalam bentuk barang dan jasa dengan mengubah input menjadi output (Heizer dan Render, 2009). Pengertian jasa menurut Kotler dan Keller (2009) bahwa Jasa adalah setiap tindakan atau kegiatan yang dapat ditawarkan oleh satu pihak ke pihak lainnya yang pada dasarnya tidak berwujud dan tidak pula berakibat kepemilikan sesuatu dan produksinya dapat atau tidak dapat dikaitkan dengan suatu produk fisik.

Komponen dasar proses antrian adalah kedatangan, pelayanan, dan antrian. Karakteristik antrian yaitu terdiri dari karakteristik kedatangan atau masukan sistem, karakteristik antrian, dan karakteristik pelayanan. Ada empat model struktur antrian dasar yang umumnya terjadi dalam seluruh sistem antrian yaitu :

1. Single Channel-Single Phase

2. Single Channel-Multi Phase

3. Multi Channel-Single Phase

4. Multi Channel-Multi Phase

Beragam model antrian dapat digunakan di bidang manajemen operasi, ada empat (4) model yang paling sering digunakan yaitu :

1. Model A: M/M/I (Single Channel Query System atau model antrian jalur tunggal).

2. Model B: M/M/S (Multiple Channel Query System atau model antrian jalur berganda).

3. Model C: M/D/1 (Constant Service atau waktu pelayanan konstan).

4. Model D: (Limited Population atau populasi terbatas).

Elwood S. Buff dan Rakeshk.Sarin (1999) memberikan ulasan tentang pengertian antrian antara lain adalah sebagai berikut :

1. Queueing atau waiting line. Deretan berbentuk yang dilakukan bila mana menunggu giliran untuk menerima pelayanan.

2. Queue Formation. Deretan berbentuk dari beberapa waktu bilamana permintaan untuk 
dilayani melampaui fasilitas pelayanan yang ada.

3. Queueing situation. Siapa saja yang sudah terdaftar terlebih dahulu itulah yang akan mendapat pelayanan pertama.

4. Queues economics. Pada kenyataannya situasi dan kondisi antrian dipengaruhi oleh perkembangan ilmu ekonomi.

5. Waiting time. Rata-rata lamanya waktu menunggu untuk mendapatkan pelayanan.

6. Holding time. Waktu yang digunakan sejak pelayanan dimulai sampai satu unit selesai dilayani.

7. The arrival pattern. Komponen antrian dapat berbentuk dari beberapa macam variasi.

8. The service pattern. Sistem pelayanan terhadap beberapa macam variasi antrian dapat secara teratur atau betul-betul memerlukan pada saat itu juga.

9. The traffic intensive. Perbandingan antara kecepatan rata-rata dan kedatangan rata-rata dan kedatangan rata-rata dalam pelayanan.

10. The number of service channels. Kedatangan dan struktur pelayanan sering kali berdasarkan urutan-urutan, tapi kadang-kadang segera memerlukan pelayanan tergantung dari saluran pelayanan.

\section{Bahan dan Metode:}

Alat analisis data model antrian jalur berganda merupakan model antrian yang terdapat dua atau lebih jalur atau stasiun pelayanan yang tersedia untuk menangani pelanggan yang akan datang. Alat analisis yang digunakan adalah model M/M/S (Multiple Channel Query System). Heizer dan Render (2006) mengatakan bahwa M/M/S artinya terdapat lebih dari satu jalur fasilitas dan hanya ada satu tahapan pelayanan yang harus dilalui oleh pelanggan untuk menyelesaikan pelayanan.

Waktu yang dibutuhkan oleh pelanggan bersifat acak (random), karena jumlah kebutuhan setiap pelanggan berbeda-beda. SPBU 34-151-28 Jatiuwung Kota Tangerang menerapkan pelayanan first-come, first-served (FCFS) dimana pelanggan yang datang pertama akan dilayani terlebih dahulu.

Uji Hipotesis diterima atau ditolaknya hipotesis penelitian ini mengacu pada hasil pengujian antrian menggunakan model $\mathrm{M} / \mathrm{M} / \mathrm{S}$ (Multiple Channel Query System atau model antrian jalur berganda). Hipotesis ini diterima apabila kinerja pelayanan sistem antrian pada SPBU 34-151-28 Jatiuwung Kota Tangerang belum optimal, yaitu waktu antrian berdasarkan model perhitungan berada diatas 0,75 menit. Sebaliknya hipotesis ini ditolak apabila kinerja pelayanan sistem antrian pada SPBU 34-151-28 Jatiuwung Kota Tangerang sudah optimal, yaitu waktu antrian berdasarkan model perhitungan $\mathrm{M} / \mathrm{M} / \mathrm{S}$ berada dibawah 0,75 menit.

\section{Hasil dan Pembahasan}

Tabel 1. Waktu Kedatangan Pelanggan

\begin{tabular}{cccc}
\hline No & Hari & Tanggal & $\begin{array}{c}\text { Waktu } \\
\text { Kedatangan } \\
\text { Pelanggan }\end{array}$ \\
\hline 1 & Senin & $2 / 7 / 2018$ & 33 menit \\
\hline 2 & Selasa & $3 / 7 / 2018$ & 99 menit \\
\hline 3 & Rabu & $4 / 7 / 2018$ & 48 menit \\
\hline 4 & Kamis & $5 / 7 / 2018$ & 122 menit \\
\hline 5 & Jum'at & $6 / 7 / 2018$ & 105 menit \\
\hline 6 & Sabtu & $7 / 7 / 2018$ & 118 menit \\
\hline \multicolumn{4}{c}{ Jumlah } \\
\hline
\end{tabular}

Pada SPBU 34-151-28 Jatiuwung terdapat empat jalur yang disediakan untuk melayani pelanggan. Jenis sistem antrian yang diberlakukan adalah jenis sistem antrian model Multiple Channel Query System atau model antrian jalur berganda (M/M/S). Dimana terdapat empat petugas yang dapat melayani para pelanggan dan proses pelayanan melalui petugas hanya satu kali.

Waktu yang dibutuhkan oleh petugas untuk melayani para pelanggan adalah bersifat random (acak). Dalam upaya mempertahankan tingkat optimalnya, proses pelayanan maka SPBU 34-151-28 Jatiuwung menetapkan standar waktu pelayanan bagi setiap petugas adalah maksimal 0,75 menit. Disiplin pelayanan yang diberlakukan oleh SPBU 64-755-01 Jatiuwung adalah disiplin pelayanan First Come First Serve (FCFS).

Tingkat kedatangan merupakan banyaknya pelanggan yang datang untuk mendapatkan pelayanan dari petugas, dinyatakan dalam beberapa banyak pelanggan (orang) dalam periode waktu tertentu. Tingkat kedatangan konsumen diasumsikan mengikuti distribusi poisson. Proses poisson sendiri adalah kedatangan pelanggan lain tidak tergantung pada waktu (tidak terbatas).Sedangkan tingkat pelayanan petugas adalah lamanya waktu 
pelayanan yang disediakan oleh petugas untuk melayani konsumen, di mana standar waktu pelayanan adalah rata-rata 0,75 menit.

Data kedatangan pelanggan diperoleh dengan cara melakukan pengamatan jumlah pelanggan yang memasuki sistem antrian pada SPBU 34-151-28 Jatiuwung. Pengamatan dilakukan pada jam 21.30 - 23.30, jumlah pelanggan yang memasuki sistem antrian pada SPBU dicatat setiap interval satu jam.

Analisis Sistem Antrian dengan Model Multiple Channel Query System atau model antrian jalur berganda (M/M/S) pada Stasiun Pengisian Bahan Bakar Umum (SPBU) 34-15128 Jatiuwung terdapat empat petugas dan empat jalur yang disediakan untuk melayani pelanggan. Tingkat kedatangan pelanggan per-jamnya dapat dicari dengan cara menjumlahkan kedatangan pelanggan tiap jam yang sama dibagi dengan 7 hari kerja. Tingkat kedatangan pelanggan per jamnya dapat dicari dengan cara menjumlahkan kedatangan pelanggan tiap jam yang sama dibagi dengan 7 hari kerja.

Tabel 2. Rata-rata Tingkat Kedatangan

\begin{tabular}{cc}
\hline \multicolumn{2}{c}{ Rata-rata Tingkat Kedatangan } \\
\hline $\begin{array}{c}\text { Periode Waktu } \\
(2 \text { jam })\end{array}$ & $\begin{array}{c}\text { Rata - rata } \\
\text { Tingkat } \\
\text { Kedatangan } \\
\text { Motor (menit) }\end{array}$ \\
\hline Senin & 5 \\
\hline Selasa & 16 \\
\hline Rabu & 8 \\
\hline Kamis & 20 \\
\hline Jum'at & 17 \\
\hline Sabtu & 19 \\
\hline
\end{tabular}

Tabel 3. Rata-rata Tingkat Pelayanan

\begin{tabular}{ccc}
\hline \multicolumn{3}{c}{ Rata-rata Tingkat Pelayanan } \\
\hline $\begin{array}{c}\text { Periode } \\
\text { Waktu } \\
(2 \text { jam })\end{array}$ & $\begin{array}{c}\text { Standar Waktu } \\
\text { Pelayanan } \\
\text { (detik) }\end{array}$ & $\begin{array}{c}\text { Tingkat } \\
\text { Pelayanan } \\
\text { Sepeda Motor }\end{array}$ \\
\hline 3074.167 & 31.42 & 97.3 \\
\hline
\end{tabular}

Tabel 4. Lawa Waktu Pelayanan

\begin{tabular}{ccc}
\hline \multicolumn{3}{c}{ Lama Waktu } \\
\hline $\begin{array}{c}\text { Standar } \\
\text { (detik) }\end{array}$ & $\begin{array}{c}\text { Terpanjang } \\
\text { (detik) }\end{array}$ & $\begin{array}{c}\text { Terpendek } \\
\text { (detik) }\end{array}$ \\
\hline 31.5 & 480 & 11 \\
\hline
\end{tabular}

Waktu rata-rata yang dihabiskan oleh seorang pelanggan untuk menunggu dalam antrian $(W q)$ : Waktu terpanjang yang diperlukan pelanggan dalam antrian adalah 480 detik

Berdasarkan analisis maka dapat disimpulkan bahwa kinerja pelayanan sistem antrian berdasarkan perhitungan model $\mathrm{M} / \mathrm{M} / \mathrm{S}$ pada SPBU 34-151-28 Jatiuwung sudah optimal, hal ini terlihat dari hasil analisis bahwa standar waktu pelayanan $(W q)$ 0,2621 menit karena waktu standar yang ditentukan adalah selama 0,75 menit.

\section{Kesimpulan}

1. Jenis sistem antrian yang diterapkan pada SPBU 34-151-28 Jatiuwung adalah jenis sistem antrian model Multiple Channel System atau M/M/S, di mana terdapat beberapa petugas yang melayani pelanggan namun fase yang dilewati pelanggan hanya satu kali melakukan transaksi / pengisian.

2. Disiplin pelayanan yang diberlakukan SPBU 34-151-28 Jatiuwung adalah disiplin pelayanan First Come First Served (FCFS), yaitu dimana pelanggan mengantri sesuai urutan untuk mendapatkan pelayanan.

3. Kinerja sistem antrian pada SPBU 34-15128 Jatiuwung, waktu terpendek yang dibutuhkan oleh seorang pelanggan dalam mendapatkan pelayanan adalah 11 detik. Waktu terpanjang yang dibutuhkan oleh pelanggan dalam mendapatkan pelayanan adalah selama 480 detik, ini menunjukan kinerja sistem antrian pada SPBU 34-15128 Jatiuwung sudah optimal karena waktu yang dibutuhkan untuk pelayanan adalah 31.5 detik

Beberapa saran untuk SPBU 34-151-28 untuk peningkatan kualitas pelayanan antara lain:

1. Kinerja sistem antrian pada SPBU 34-15128 Jatiuwung sudah optimal. Tapi masih perlu ditingkatkan lagi dari segi pelayanan petugas yaitu keramahan dan kenyamanan agar pelanggan yang mengantri merasa nyaman.

2. Petugas juga harus memperhatikan jalur mana yang akan dibuka atau ditutup karena itu dapat membingungkan pelanggan, jika petugas ingin beristirahat maka lebih baik melakukan rolling kepada sesama petugas, dan tidak melakukan pergeseran pada antrian.

3. Dari segi keamanan SPBU pun harus diperhatikan agar tidak terjadi hal yang 
tidak diinginkan seperti adanya mobil yang parkir terlalu lama pada pintu masuk karena itu dapat membuat antrian bertambah panjang atau mengganggu pelayanan SPBU.

\section{Daftar Pustaka}

Elwood S. Buff \& Rakesh K. Sarin (1999). Manajemen Operasi dan Produksi Modern. Binarupa Aksara : Jakarta

Heizer, Jay \& Rander, Barry (2004), Manajemen Operasi (edisi ketujuh), Salemba Empat : Jakarta

Kotler, Philip \& Kevin Lane Keller (2009), Manajemen Pemasaran (edisi ke-12). Indeks: Jakarta

Siken.H, Eddy Soegiarto K, Adi Suroso. Antrian pada Stasiun Pengisian Bahan Bakar Umum (SPBU) 64-755-01 Blintut Barong Tongkok Kutai Barat Manajemen, Fakultas Ekonomi, Universitas 17 Agustus 1945 Samarinda 75234, Indonesia.

Soegito, Eddy Soeryatno (2007), Marketing Research : Panduan bagi Manajer Pemimpin Perusahaan Organisasi, Elex Media Komputindo: Jakarta 